\title{
Gelişimsel kalça displazisi zemininde gelişen artrozların tedavisinde total kalça artroplastisi
}

\section{Total hip arthroplasty in the treatment of arthritis developing on the basis of developmental dysplasia of the hip}

\author{
Burak Akan, illker Çetin \\ Ufuk Üniversitesi Tıp Fakültesi, Ankara, Türkiye
}

Gelişimsel kalça displazisi kalçanın sekonder osteoartritinin en sık görülen sebeplerinden biridir. Total kalça artroplastisi (TKA) osteoartritli kalçada ağrının geçirilmesinde ve fonksiyonların iyileştirilmesinde etkili bir cerrahi olmasına rağmen, TKA'nın gelişimsel kalça displazisine bağlı osteoartritte uygulanması zordur. Gercek asetebulumun tanımlanması ile hazırlanması, femoral kanalın hazırlanması ve komponentlerin redüksiyonu önemli tekniksel problemler ortaya çıkarır. Bu yazıda erişkin gelişimsel kalça displazisinde sınıflamalara göre TKA ile rekonsrüksiyonun özellikleri tartışılmaktadır.

Anahtar sözcülkler: replasman artroplastisi, kalça; kalça protezleri; GKD
Developmental hip dysplasia are one of the most common reasons for secondary osteoarthritis of hip. Although total hip arthroplasty (THA) is an effective surgery for relieving pain and improving function in an osteoarthritic hip, application of THA for osteoarthritis which is secondary to developmental dysplasia of the hip is difficult. The identification and prepation of the true acetebulum, the prepation of the femoral canal, and reduction of the components pose important technical problems. In this article, features of reconstruction with THA are discussed depending on classification of development dysplasia of hip.

Key words: replacement arthroplasty, hip; hip prosthesis; $\mathrm{DDH}$

kalçada ve dizde dejeneratif osteoartrit, aynı taraf dizde ise valgus ve lateral kompartman artrozu, lomber vertebralarda zamanla yapısal skolyoz ve faset eklemlerde meydana gelen dejeneratif olaylara bağıı olarak da ağrı görülür. Eğer GKD iki taraflı ise lomber lordoz artar, her iki dizde valgus deformiteleri görülür, hastalar çabuk yorulur ve hareketleri sınırlıdır. Cerrahi öncesi bu yukarıda bahsedilen örneklerdeki gibi ek deformite ve anomaliler iyi tespit edilmeli ve daha uzun süreli ve tatmin edici rekonstrüksiyonun önündeki engeller aşılmalıdır. Ameliyat endikasyonu için en önemli bulgu kalça ağrısıdır. Aynı zamanda hastada sırt ve diz ağrısı da olabilir. Hastalar aksayarak yürümekten veya yürüme destek cihazlarından kurtulmak isteyebilirler. Aksama, ekstremitenin kısalığı ve fonksiyonunda azalmaya bağlı olabilir, ancak aksama bu genç hastalarda tek başına bir ameliyat endikasyonu değildir. Hasta günlük aktivitelerini arada bir aldığı ağrı kesici ilaçlar ile sürdürebiliyorsa ameliyat kararı vermekte acele etmemek gerekir.

- İletişim adresi: Dr. Burak Akan, Ufuk Üniversitesi Tıp Fakültesi Ortopedi ve Travmatoloji Anabilim Dalı. Ankara, Türkiye Tel: 0505 - 5025327 e-posta: burakakan1977@yahoo.co.uk

- Geliș tarihi: 27 Mart 2013 Kabul tarihi: 12 Haziran 2013 

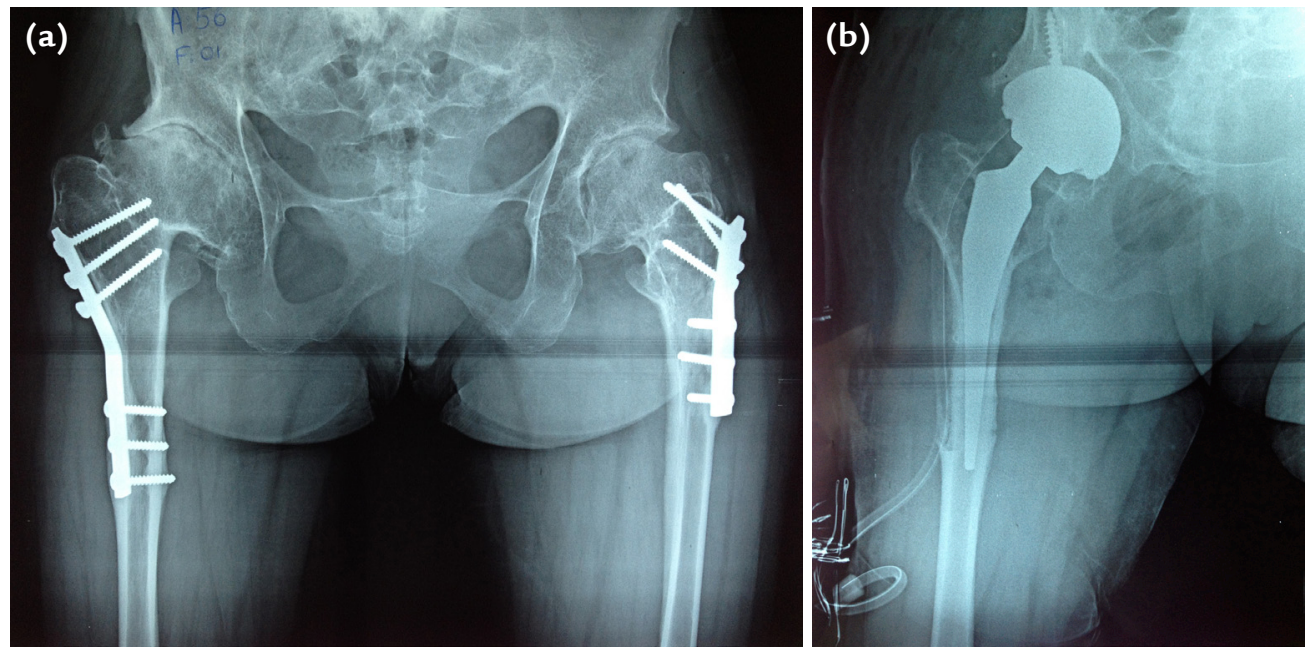

Şekil 1. 33 yaşında kadın hasta çift taraflı GKD’si (a). Önceden geçirilmiş ameliyatlar femoral anatomiyi daha karmaşık hale getiriyor. Sağ kalça ameliyat sonrası görüntüsü (b).

\section{ANATOMI}

GKD'de uzun süreli tatmin edici sonuçların alınabilmesi için klinik durumun ve radyolojik anatominin iyi anlaşılması gerekir. Anatomi çocukluk yaşında geçirilmiş ameliyatlar ile daha da karmaşık hale gelmiş olabilir.

\section{Asetabulum}

GKD'de femur başı gerçek asetabulumun içindeyse, superiorda kısmi segmantal defekt vardır ve asetabular fossa içerisinde derinliği azaltan osteofit bulunur. Asetabulumun girişi geniş ve ovaldir. Alçak dislokasyonda femur başı yalancı asetabulum ile eklem yapar, femur başı ile yalancı asetabulum gerçekasetabulumun proksimalinde ve devamı şeklindedir. Superiordaki segmental defekte ilaveten, anteriorda da segmental defekt ve derin olmayan bir asetabulum bulunur. Nadiren de, posteriordaki kemik stoğu azalmıştır. Yüksek çıkıklarda, femur başı hipoplastik ve gerçekasetabulumun superio-posteriorundadır. Asetabulumun bütün kenarlarında segmental defekt vardır. Asetabulum sığ olup, dar bir açıklığı vardır. Asetabulumun posterosuperiorunda kemik stoğu iyi olup, anteversiyonda artış vardır. iliak kemik hipoplastik ve anteverttir.

\section{Femur}

GKD'de femurun proksimal kısmı normaldir, alçak çıkıkta femur boynu kısadır, yüksek çıkıkta femur boynu daha da kısa olup ileri derece anteverttir. Diafizde hipoplastik kanal dar ve çoğunlukla korteksler incedir. Femurun anterior-posterior çapı medial-lateralden daha geniş̧ir. ${ }^{[1]}$ Boyun şaft açısı displazinin artması ile ters orantılı olarak azalır; eğer radyografilerde valgus görünümü varsa, bu femur boynunun artmış anteversiyonuna bağlı olabilir.

\section{Yumuşak dokular}

Özellikle ilio-psoas, adduktorlar ve rektus femoris kasları kontraktedir. Femurun proksimal migrasyonu, abduktor kas kitlesinin göreceli olarak yatay yönelimine yol açar. Aynı zamanda, abduktorlar kısa ve az gelişmiştir. Kalça kapsülü hipoplastik asetabulumun kenarından başlayıp önce daralır, sonra genişleyerek femur başını sararak kum saati görünümü alır. Siyatik sinir kısalmış olup, eğer ameliyat esnasında gereğinden fazla ekstremite uzatması yapılırsa risk altına girer. Femoral sinir ve femoral arter de aynı şekilde uzatma esnasında gerilebilir.

\section{SINIFLAMA}

Displastik kalçada geniş bir anomali yelpazesi görülür, herbirinin kendine has zorlukları vardır ve farklı çalışmalardaki bulguların karşılaştırılabilmesi için sınıflama sistemine ihtiyaç vardır. Birçok sınıflama sistemi tarif edilmiştir. Bunlardan aşağıda kısaca bahsedilmiştir, ancak yazarların sonuçlarını bildirebileceği dünyaca kabul görmüş ortak bir dile ihtiyaç duyulduğu açıktır.

Crowe ve arkadaşlarının sınıflamasına göre, displastik kalçalar femur başının proksimale migrasyonuna göre dört katagoriye ayrılmışlardır. ${ }^{[2]}$ Radyolojik değerlendirmede referans noktaları olarak genellikle, pelvisin yüksekliği, femur başı ile boynu arasındaki birleşim bölgesi ve gözyaşı damlası kullanılır. Femur başının büyüklüğü pelvis yüksekliğinin \%20'si olarak kabul edilir. Sınıflamada esas alınan ölçümler, 

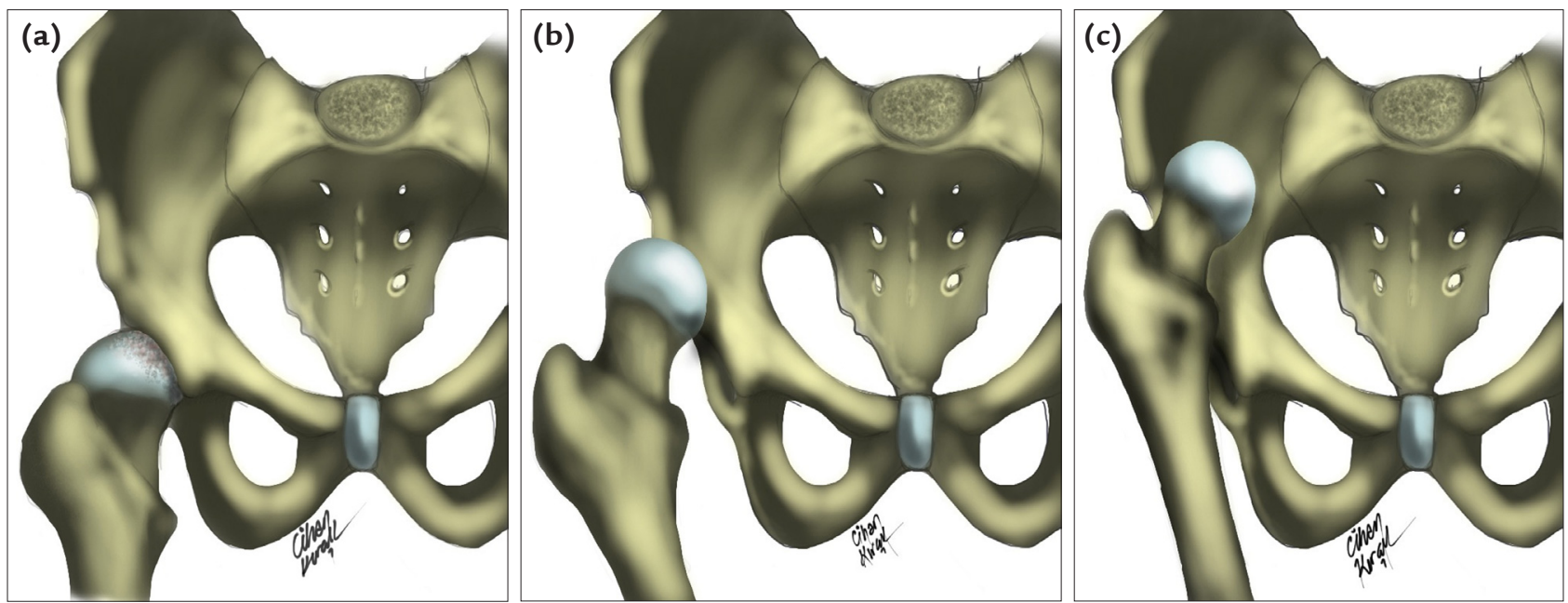

Şekil 2. Hartoflakidis Sınıflaması: Displazi (a), Alçak Çıkık (b), Yüksek Çıkık (c).

gözyaşı damlasının alt noktası ile baş-boyun birleşme yeri arasındaki bölgede yapılır. Normal kalçalarda bu referans yerleri yaklaşık olarak aynı seviyelerdedir. Femur başının proksimale migrasyon miktarı, pelvis yüksekliğinin ya da başın yüksekliğinin yüzdesi olarak kabul edilir.

Sınıf I: Pelvis yüksekliğinin \%10'undan veya femur başının büyüklügünden $\% 50$ daha az proksimal migrasyon.

Sınıf II: Pelvis yüksekliğinin \%10-15'i veya femur başı büyüklüğünün \%50-75'i kadar proksimal migrasyon.

Sınıf III: Pelvis yüksekliğinin \%15-20'si veya femur başı büyüklüğünün \%75-100'ü kadar proksimal migrasyon.

Sınıf IV: Pelvis yüksekliğinin \%20'sinden veya femur başı büyüklüğünün \%100'ünden daha fazla proksimal migrasyon.

Hartoflakidis ve ark. ${ }^{[3]}$ displazi ve kalça çıkığını, displazi (alçak veya subtotal), alçak çıkık (ya da subtotal çıkık) ve yüksek çıkık (ya da tam çıkık) olmak üzere üç katagoriye ayırmışlardır (Şekil 2). Displazide femur başı sublukse, ancak gerçek asetabulumun içindedir. Asetabular fossa içindeki osteofit derinliği azalmaktadır ve superior duvarda segmental noksanlıklar vardır. Alçak çıkıkta femur başı orijinal asetabulumun proksimalinde ve kısmen de onu sınırlayan neokotil ile eklemleşir. Bunlarda, asetabulumun anterior ve superior kenarlarında segmental defekt vardır. Asetabulum sığ ve olgunlaşmamıştır. Yüksek çıkıkta femur başı yüksekte ve posteriordadır; iliumda bir çukur ile eklem yapar. Orijinal asetabulumun bütün kenarlarında defekt vardır. Asetabulum anteverttir ve girişi dardır. Posterosuperiorda bir miktar kemik stoğu bulunur.

Kerboul ve ark. ${ }^{[4]}$ displastik veya çıkık kalçaları femurun patolojik anatomisinin durumuna göre, anterior, intermediate (orta) ve posterior olmak üzere sınıflamışlardır. Anterior sınıflama alçak subluksasyonlar için, intermediate yüksek subluksasyonlar için ve posterior yüksek, stabil olmayan çıkıklar için kullanılmıştır.

Mendes ve ark.[1] sınıflamalarında, yetişkin kalça displazisinde total kalça artroplastisini planlamayı amaçlamışlardır. Yüksek ve sublukse olmak üzere başlıca iki geniş tipten bahsetmişlerdir. Burada esas olan kemik stoğudur. İkincisi, yumuşak dokuların kontraktürleri ve kas yetmezlikleridir. Üçüncü durum ise, pelvik çarpıklık (obliquity), lumbal eğrilikler, dizin valgus deformiteleri ve bacaktaki uzunluk problemlerini ele alır. Bu sistem, displastik kalçada replasmanın planlanmasında faydalı bir algoritma ortaya koyar. Fakat değişik merkezlerin sonuçlarını karşılaştırmada ölçüm olanağı vermez.

Biz kendi pratiğimizde ölçüm ve kullanım kolaylığı olan Hartofilakidis ve arkadaşlarının tarif ettiği sınıflamayı kullanmaktayız. ${ }^{3]}$

\section{AMELIYAT ÖNCESI PLANLAMA VE REKONSTRÜKSIYON}

Displastik kalçada tedavi, hastalığın derecesine, sekonder osteoartritik değişikliklerin durumuna, hastanın yaşına, fonksiyonel beklentisine ve elde bulunan kemik stoğuna bağlıdır. Önceden geçirilmiş ameliyatlara bağlı değişmiş anatomiyi anlamak, cerrahi öncesi planlamada çok önemlidir. 
Ameliyattan önce aynı film kasedine her iki kalçanın 1:1 ölçekte ön-arka direkt grafisi çekilir. Displazide ve yüksek çıkıkta genellikle bu grafi, pratikte ameliyat öncesi planlama için yeterlidir. Bazen kemik stoğunu daha iyi anlamak için standart radyografiler Judet grafileri ile desteklenmelidir. Alçak çıkıkta, ameliyat edilecek tarafın bilgisayarlı tomografi (BT) görüntülerine intiyaç olabilir. Segmental defektin yeri ve büyüklüğü ile asetabulumun bütünlüğü ve çapı hesaplanır. Femurun anteversiyonu da BT yardımı ile daha iyi anlaşılabilir. Gerekirse üç boyutlu görüntüler de kullanılabilir. Şablonlama, GKD zemininde yapılacak TKA için bize göre yaşamsal öneme sahiptir. Doğru büyütmede çekilmiş direkt grafiler üzerinden yapılan şablonlama ile, asetabuler komponentin çapı ve konumu ile proksimal femoral komponentin tipi ve büyüklüğü tespit edilir.

GKD için uygulanan TKA'da en zor aşama, alçak çıkıkta asetabulumun rekonstrüksiyonudur. Yüksek çıkıklar$\mathrm{da}$, genellikle asetabulum femurla hiç eklem yapmamıştır ve şekilleri itibariyle benzerlik gösterirler. Asetabulumun girişi, tepesi ilium tarafinda olan bir üçgene benzer, bütün kenarları az gelişmiştir; ama özellikle anterior duvar, hem çok ince hem de segmental defektlidir. En iyi kemik stoğu posteriorda bulunur. Çoğunlukla herhangi bir kemik greftine ihtiyaç duyulmadan 40, 42 veya 44 mm büyüklüğünde asetabuler kap yerleştirilebilir. Yüksek kalça çıkıklarında en iyi kemik stoğunun gerçek asetabulumda olduğunu unutmamak gerekir. Ayrıca, biyomekanik olarak da orijinal asetabuluma protez yerleştirmek daha uygundur. Yüksek çıkıkta femoral komponentin orijinal asetabuluma yerleştirilen asetabuler komponentin karşısına gelebilmesi için kısaltma osteotomisi uygulanır. Siyatik sinir ve femoral arteri $2,5-3 \mathrm{~cm}$ 'ye kadar uzatmak, emniyetli sınırlar içerisindedir. Adduktör tenotomi, iliopsoas tendonunun kesilmesi, bu uzatmanın miktarını arttırarak emniyetli sınııı dışına çıkılmasına ve paralizilere sebep olabilir.

Alçak çıkıklarda, asetabulumda, özellikle superiorda (ilium tarafında) segmental defekt vardır. Bu defekt, femur başı kullanılarak kapatılmalı ve böylece asetabuler kabın primer stabilitesi sağlanmalıdır. Eğer uzama miktarı 2,5-3 cm'yi geçmiyorsa subtrokanterik kısaltmaya ihtiyaç duyulmayabilir.

\section{CERRAHI TEKNIK}

Anterolateral, direkt lateral ya da posterior girişimlerin herhangi biri tercih edilebilir. ${ }^{[5]}$

Biz kendi pratiğimizde, supin pozisyonda direkt lateral yaklaşımı kullanıyoruz. Cilt kesisini kalça $20^{\circ}$ fleksiyonda, $30^{\circ}$ adduksiyonda ve $10^{\circ}$ iç rotasyonda iken uyguluyoruz. Cilt kesisi, büyük trokanterin 2-3 cm proksimaliden başlayıp femurun lateralinden distale doğru 15-20 cm uzanır. Cilt kesisinin uzunluğu, subtrokanterik kısaltma osteotomisine ve hastanın obezite durumuna göre değişir. Fasya, cilt kesisi doğrultusunda ve aynı uzunlukta kesilir. Trokanter majörün lateraline yapışmış olan gluteus medius kasının 1/3 anteriorundan girilerek kapsül ortaya çıkarılır. Kapsülün anterioruna, superioruna ve inferioruna birer adet Hohmann ekartörü konulur. Kapsül boyun doğrultusunda kesilir; superior yarısı çıkarılır. Hohmann ekartörleri tekrar kapsül içerisine, boynun superior ve inferioruna konur. Kalça $90^{\circ}$ fleksiyon ve dış rotasyona getirilerek lukse edilir. Boyun genellikle trokanter minörün $1 \mathrm{~cm}$ proksimalinden kesilir. Ameliyatın bu aşamasına kadar GKD'nin displazi, alçak çıkık veya yüksek çıkık evresinde olması fark etmez.

\section{Displazide}

Asetabulumun posterioruna, inferioruna ve anterioruna olmak üzere 3 adet Hohmann ekartörü yerleştirilir. Eğer hasta çok sişman ise superiora bir veya iki adet Steinmann çivisi, gluteal kasları ekarte etmek için çakılır. Asetabulum ovaldir, uzun ekseni proksimal distal yöndedir. Asetabuluma yerleştirilecek kabın büyüklüğünü, anterio-posterior (oval asetabulumun küçük çapı) çapın boyutları belirler. Böylece kap ya distale yerleştirilir ve süperioru femur başından elde edilen kemik grefti ile doldurulur ya da bizim pratiğimizde daha çok tercih ettiğimiz gibi, proksimale yerleştirilerek, greft kullanmaya gerek kalmadan stabil fiksasyon elde edilebilir. Displazide femurun bir özelliği yoktur, primer TKA'daki uygulamanın aynısıdır.

\section{Alçak çıkıkta}

Asetabulumun superior kenarında kısmen veya tamamen segmental defekt vardır. Bu defekte bakılmaksızın asetabulumun içinden obturatuar deliğe yerleştirilen Hohmann ekartörü bize gerçek asetabulumun nerede olması gerektiğini gösterir. Asetabulumun ön-arka çapına uygun şekilde oyma işlemi asetabulumun tabanına kadar yapılır. Superior segmantal defekt, kapın stabilitesini bozacak şekilde ise femur başından elde edilen greft defekti dolduracak ve kabın stabiltesini destekleyecek şekilde vidalanır. Femurun anteversiyonu artmış ise, medullanın geniş çapı anteversiyon yönünde şekillenir; böyle durumlarda, kesiti dikdörtgen olan protezlerin yerine her yönde stabil olan kesidi yuvarlak 'cone' tarzı protezler tercih edilmelidir. Genellikle femura kısaltma osteotomisi gerekmez (Şekil 3).

\section{Yüksek çıııkta}

Ameliyata femurdan başlanır. En küçük boydan başlanarak femoral meduller kanal raspalanır. Raspalama 

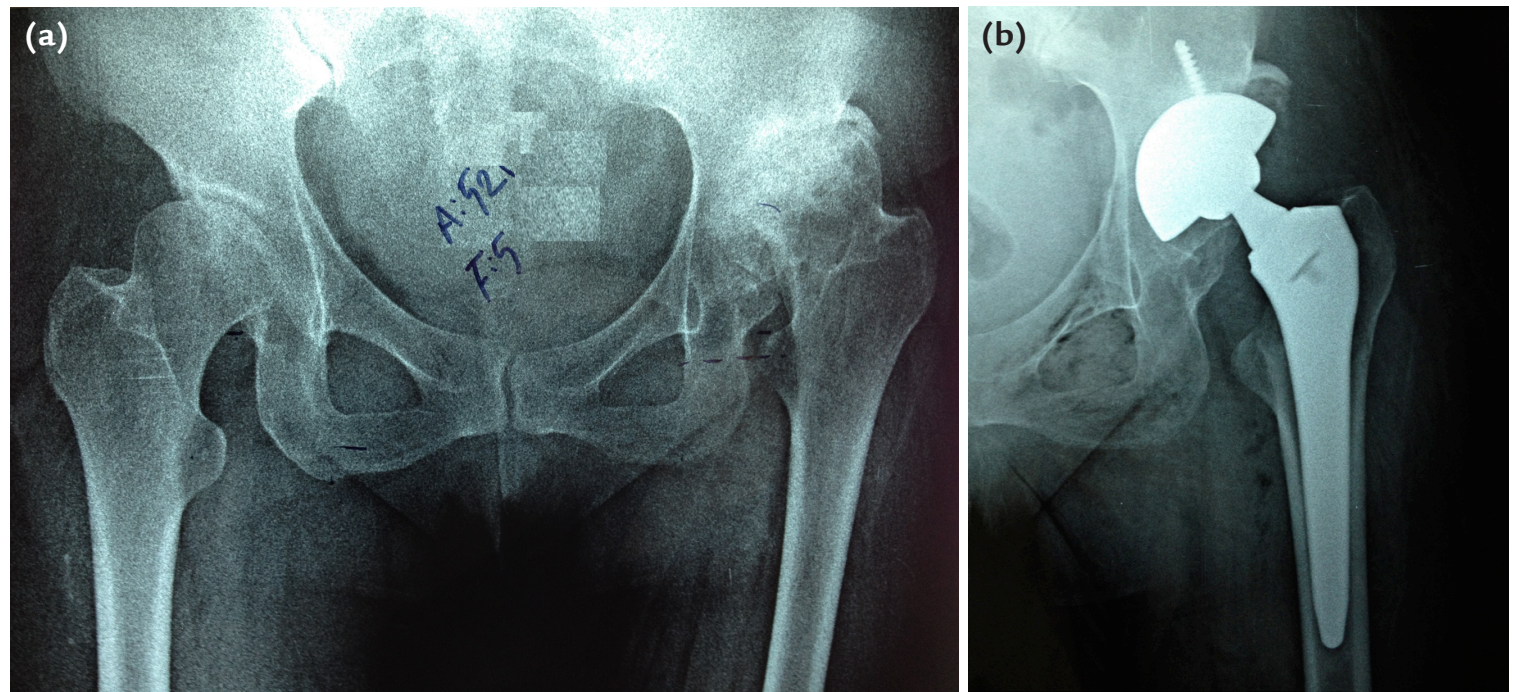

Şekil 3. Kırk dokuz yaşında kadın hasta. Hartoflakidis alçak çıkık ameliyat öncesi radyografik görüntü (a). Ameliyat sonrası radyografik görüntü (b).
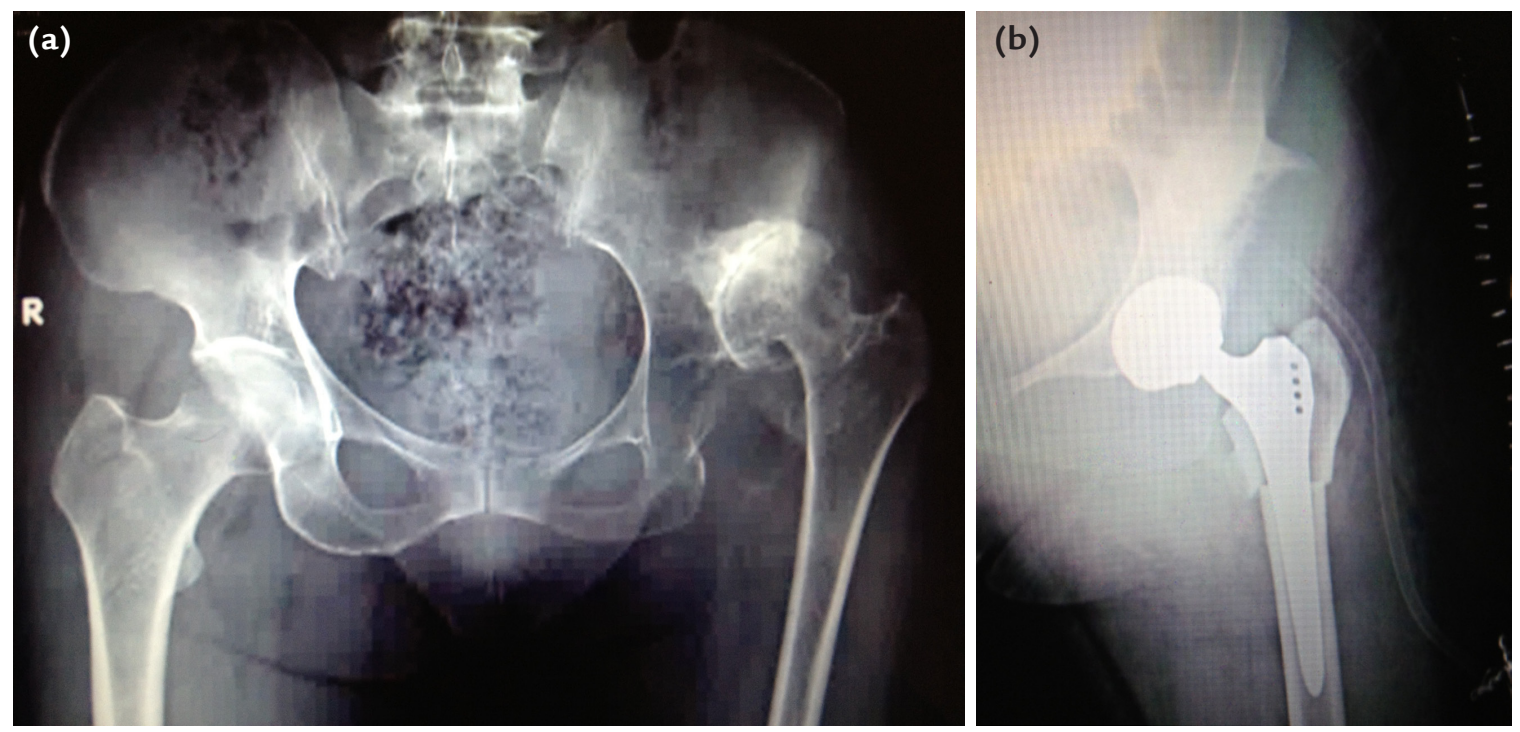

Şekil 4. Kırk dört yaşında kadın hasta. Hartoflakidis yüksek çıkık ameliyat öncesi radyolojik görüntü (a). Ameliyat sonrası radyolojik görüntü (b). Transvers subtrokanterik osteotomi ve rotasyonel stabilite için ekstra bir tespit materyali yok.

işlemi sonrası trokanter minörün $5 \mathrm{~mm}$ distalinden subtrakenterik transvers osteotomi yapilır. Rezeksiyon miktarı femurun yükseklik miktarına bağlıdır. Genellikle "Rezeksiyon miktarı $(\mathrm{cm})=$ Yükseklik miktarı $(\mathrm{cm})$ 2,5" olarak formülleştirilebilir. Rezeksiyon sonrası gerçek asetabulum görülebilir hale gelir. Asetabulumun distaline (obturatuar foremenin proksimaline), anterioruna ve posterioruna olmak üzere üç adet Hohmann ekartörü konur. Öncelikle asetabulum içerisindeki pulvinar doku temizlenir. Kemik stok ve derinlik kontrol edilir. Genellikle anterior duvar ince ve az gelişmiştir, segmental defekt vardır. En iyi kemik stok posterior duvardadır, superior duvar ise posterior kenardan az ama anterior duvardan çok kemik stoğu içerir. Asetabuler oyma işlemine $36 \mathrm{~mm}$ gibi küçük oyucular ile başlanır ve zaten zayıf kemik stoğuna sahip anterior duvarı bozmamak için, posteriora doğru yönlendilir. Sırasıyla oyucular büyütülerek asetabulum hazırlanır. Burada kemik süngersi yapıda olduğu için, oyucudan $2 \mathrm{~mm}$ daha büyük kap yerleştirmek mümkündür. Böylece stabil tespit sağlanır; greft kullanmaya gerek yoktur. Femurda daha önceden kısaltma osteotomisi yapıldığından, eğer distalden tutunan ve aynı zamanda proksimal parçayı da tespit edebilen bir çimentosuz protez tercih edilirse, plak gibi ekstra bir femoral tespit materyaline gerek kalmaz (Şekil 4). 


\section{TARTIŞMA}

Displastik kalça için yapılan TKA kompleks bir problem olup, birçok cerrahi zorluk içerir. Charnley ve Feagin tedavi edilmemiş konjenital çıkıklı kalçalarda TKA'nın, yeterince asetabuler kemik stoğu olmadığı için, kontrendikasyon olarak kabul görmesini önermişlerdir. ${ }^{[6]}$ Başarı için, ameliyat öncesi değerlendirme tam olarak yapılmalıdır. Asetabuler kap gerçek asetabuluma yerleştirilmelidir ki, normal bir biyomekanik elde edilebilsin. Total kapsülotomi gereklidir, ancak tenotomiler rutin olarak yapılmamalıdır. Tendonların sağlam olması, siyatik sinir, femoral sinir ve femoral arteri korur, kas kuvvetlerinin iletilmesini sağlar. Asetabuler kabın uzun ömürlü olabilmesi için, mümkün olan en fazla kemik ile örtülmesi ve stabil bir tespit sağlanması gereklidir. Eğer $3 \mathrm{~cm}$ 'den daha fazla bir uzatma yapılmış ise, ameliyat sonrası dönemde kalça ve diz fleksiyonda tutularak damar ve sinirlerdeki gerginlik azaltılmalıdır.

İmplant seçiminde dikkatli olunması gerekir. Mümkünse, ameliyat esnasında birkaç alternatif elimizin altında olmalıdır. Çimentolu asetabuler kaplar kullanıldığında, erken başarısızık sonuçları bildirilmiştir. ${ }^{[7-9]}$ Chougle ve ark. ${ }^{[10]}$ bu başarısızlıkların nedeni olarak yetersiz mediyalizyonu göstermişlerdir. Ancak kapın mediyalize edilmesi ile oluşabilecek en önemli sorun, sıkışma nedeniyle anterior çıkık oluşabilmesidir. ${ }^{[11]}$ Çimentosuz ve gerçek asetebulama yerleştirilen kaplar ile uzun dönem iyi sonuçlar bildirildiği için, bu hastalarda tercih çimentosuz kap lehine olmalıdır. ${ }^{12-}$ 14] Bunlar, primer TKA hastalarına nazaran 10-15 yıl daha genç olduklarından seramik-seramik, yüksek çapraz bağlı polietilen-seramik ya da E vitaminli (E-poly) polietilen-seramik gibi uzun ömürlü bileşimler kullanılmalıdır. Femur için birçok kısaltma osteotomisi tarif edilmiştir. En çok kullanılanlar subtrokanterik osteotomiler olmasına rağmen, büyük trokanter seviyesinden yapılan osteotomileri de kullanan cerrahlar vardır. Subtrokanterik osteotomi, transvers, oblik, basamaklı ya da chevron tipinde olabilir. ${ }^{[12-17]}$ Osteotominin rotasyonel stabilitesi için özellikle kablo, vida ile tespit ya da plak kullanılabilir. ${ }^{[13,18]}$ Biz kendi pratiğimizde, fazladan bir tespit materyali kullanmıyoruz; rotasyonel stabiliteyi, seçmiş olduğumuz çimentosuz dikdörtgen kesit protezin özellikleri ile elde ediyoruz.

\section{SONUÇ}

GKD'de TKA uygulaması hastalı̆̆ın derecesine bağlı olarak çeşitli problemler içerir. Ameliyat öncesi planlama, her türlü olasılık göz önünde tutularak çok dikkatli bir şekilde yapılmalıdır; mutlaka hastaların beklentileri dedeğerlendirilerek TKA'ya karar verilmelidir.

\section{KAYNAKLAR}

1. Mendes DG, Said M, Aslan K. Classification of adult congenital hip dysplasia for total hip arthroplasty. Orthopedics 1996;19(10):881-7.

2. Crowe JF, Mani VJ, Ranawat CS. Total hip replacement in congenital dislocation and dysplasia of the hip. J Bone Joint Surg Am 1979;61(1):15-23.

3. Hartofilakidis G, Stamos K, Karachalios T, loannidis $T$, Zacharakis N Congenital hip disease in adults. Classification of acetabular deficiencies and operative treatment with acetabuloplasty combined with total hip arthroplasty. J Bone Joint Surg Am 1996;78(5):683-92.

4. Kerboul M, Mathieu M, Sauzieres P. Total hip replacement for congenital dislocation of the hip. In: Postel M, Kerboul M, Evrard J, Courpied JP, editors. Total Hip Replacement. New York, NY: Springer; 1987. p. 51-66.

5. Haddad FS, Masri BA, Garbuz DS, Duncan CP. Primary total replacement of the dysplastic hip. Instr Course Lect 2000;49:23-39.

6. Charnley J, Feagin JA. Low-friction arthroplasty in congenital subluxation of the hip. Clin Orthop Relat Res 1973;(91):98-113.

7. Sochart DH, Porter ML. The long term results of Charnley lowfriction arthroplasty in young patients who have congenital dislocation, degenerative osteoarthrosis, or rheumatoid arthritis. J Bone Joint Surg 1997;79(11):1599-617.

8. Numair J, Joshi AB, Murphy JC, Porter ML, Hardinge K. Total hip arthroplasty for congenital dysplasia or dislocation of the hip. Survivorship analysis and long-term results. J Bone Joint Surg 1997;79(9):1352-60.

9. Gerber SD, Harris WH. Femoral head autografting to augment acetabular deficiency in patients requiring total hip replacement. A minimum five-year and an average seven-year follow-up study. J Bone Joint Surg 1986;68)8):1241-8.

10. Chougle A, Hemmady MV, Hodgkinson JP. Severity of hip dysplasia and loosening of the socket in cemented total hip replacement. A long-term follow-up. J Bone Joint Surg Br 2005;87(1):16-20.

11. Saglam N, Sener N, Beksaç B, Tozun IR. Total hip arthroplasty and problems encountered in patients with high-riding developmental dysplasia of the hip. Acta Orthop Traumatol Turc 2002;36(3):187-94.

12. Erdemli B, Yilmaz C, Atalar H, Güzel B, Cetin I. Total hip arthroplasty in developmental high dislocation of the hip. J Arthroplasty 2005;20(8):1021-8.

13. Sener N, Tözün IR, Aşik M. Femoral shortening and cementless arthroplasty in high congenital dislocation of the hip. J Arthroplasty 2002;17(1):41-8.

14. Kim M, Kadowaki T. High long-term survival of bulk femoral head autograft for acetabular reconstruction in cementless THA for developmental hip dysplasia. Clin Orthop Relat Res 2010;468(6):1611-20. CrossRef

15. Anwar MM, Sugano N, Masuhara K, Kadowaki T, Takaoka $\mathrm{K}$, Ono K. Total hip arthroplasty in the neglected congenital dislocation of the hip. A five- to 14-year follow-up study. Clin Orthop Relat Res 1993;(295):127-34.

16. Becker DA, Gustilo RB. Double-chevron subtrochanteric shortening derotational femoral osteotomy combined with total hip arthroplasty for the treatment of complete congenital dislocation of the hip in the adult. Preliminary report and description of a new surgical technique. J Arthroplasty 1995;10(3):313-8

17. Yasgur DJ, Stuchin SA, Adler EM, DiCesare PE. Subtrochanteric femoral shortening osteotomy in total hip arthroplasty for high-riding developmental dislocation of the hip. J Arthroplasty 1997;12)8):880-8.

18. Paavilainen T, Hoikka V, Paavolainen P. Cementless total hip arthroplasty for congenitally dislocated or dysplastic hips. Technique for replacement with a straight femoral component. Clin Orthop Relat Res 1993;(297):71-81. 